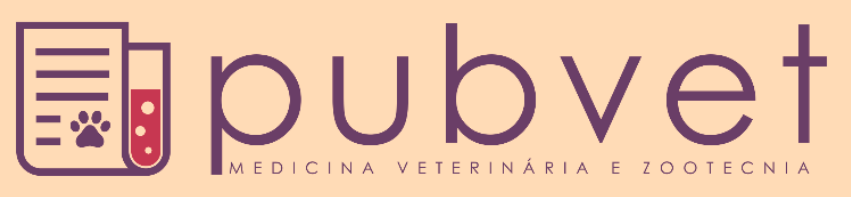

https://doi.org/10.31533/pubvet.v14n1a498.1-14

\title{
Maus tratos aos animais em manifestações culturais: uma análise sobre a perspectiva jurídica
}

\author{
Beatriz Peres Amorim ${ }^{l}$, Cláudia Elaine Costa de Oliveira $^{2} \bullet$, Graciele Araújo de Oliveira Caetano ${ }^{3 *} \bullet$ \\ ${ }^{1}$ Bacharel em Direito pela Faculdade de Jussara/GO. \\ ${ }^{2}$ Profa. Ma. Coordenadora do Curso de Direito da Faculdade de Jussara. \\ ${ }^{3}$ Prof ${ }^{a}$ Ma, Universidade Federal de Goiás Faculdade de Jussara, Brasil \\ *Autor para correspondência, E-mail: gracielecaetano@outlook.com
}

\begin{abstract}
Resumo. O presente artigo tem como objetivo compreender o modo de vida de animais em manifestações culturais, mais especificamente os que são treinados para o rodeio. Violências de todo gênero, por ação ou omissão, suscitam reações de indignação e comiseração da sociedade e desafiam a ordem jurídica. Sendo assim, o artigo irá demonstrar parâmetros legais que garantam sobrevivência e bem estar dos profissionais do rodeio e dos animais, evitando dessa forma a possível submissão ao sofrimento. Os instrumentos utilizados que eles participam são especificados no trabalho buscando assim evidenciar possíveis torturas. O ordenamento jurídico brasileiro possui parâmetros que coíbem atos cruéis contra os animais, porém a liberdade cultural, prevista constitucionalmente, por vezes ampara esse tipo de prática. Diante disso, considerando-se a necessidade de proteger o meio ambiente natural e a integridade física dos animais utilizados em eventos esportivos como o rodeio, percebe-se a necessidade de haver uma fiscalização mais abrangente e uma pena mais rigorosa, mostrando assim que estes crimes devem ser temidos e respeitados. Desse modo, a pesquisa indutiva foi o caminho bibliográfico percorrido pelo presente estudo.
\end{abstract}

Palavras Chave: Manifestações culturais, maus tratos, instrumentos, projeto de Lei $n^{\circ}$ 4.564/2016, fiscalização

\section{Mistreatment of animals in cultural events: an analysis of the legal perspective}

\begin{abstract}
This article aims to understand the animal utilization in cultural manifestations, more specifically those who are trained for rodeo. Violence of every kind, by action or omission, make indignation and commiseration reactions of society and defy the legal order. Thus, the article will demonstrate legal parameters that guarantee the survival and welfare of rodeo and the animal professionals, thus avoiding the possible submission to suffering. Instruments used and modalities that they participate are specified in the work, thus seeking to highlight possible tortures. The Brazilian legal system has parameters that curb cruel acts against the need to protect the natural environment and the physical integrity of animals used in sporting events such as rodeo, it is necessary to have a more comprehensive inspection and a more rigorous penalty, thus showing that these crimes should be feared and respected. Thus, the inductive research was the bibliographic path covered by the present study.
\end{abstract}

Keywords: cultural manifestation, animal abuse, instruments, proposed Law n ${ }^{\circ} 4.564 / 2016$, inspection 


\section{Maltrato de animales en eventos culturales: un análisis de la perspectiva legal}

Resumen. El presente artículo tiene como objetivo comprender el modo de vida de animales en manifestaciones culturales, más específicamente los que son entrenados para el rodeo. Violencias de todo género, por acción u omisión, suscitan reacciones de indignación y conmiseración de la sociedad y desafían el orden jurídico. Por lo tanto, el artículo mostrará parámetros legales que garanticen la supervivencia y el bienestar de los profesionales del rodeo y de los animales, evitando así la posible sumisión al sufrimiento. Los instrumentos utilizados que participan se especifican en el trabajo buscando así evidenciar posibles torturas. El ordenamiento jurídico brasileño posee parámetros que cohiben actos crueles contra los animales, pero la libertad cultural, prevista constitucionalmente, a veces ampara ese tipo de práctica. En vista de ello, considerando la necesidad de proteger el medio ambiente natural y la integridad física de los animales utilizados en eventos deportivos como el rodeo, se existe la necesidad de una inspección más completa y una sentencia más estricta, lo que demuestra que estos crímenes deben ser temidos y respetados. Por consiguiente, la investigación inductiva fue el camino bibliográfico recorrido por el presente estudio.

Palabras clave: Manifestaciones culturales, malos tratos, instrumentos, proyecto de Ley $n^{\circ} 4.564 / 2016$, fiscalización

\section{Introdução}

O presente artigo visa examinar, sob o ponto de vista jurídico, a realidade do rodeio no cenário ambiental brasileiro. As práticas culturais em nosso país, entendidas fundamentalmente como atividade de recepção e produção cultural, e que estão claramente associadas aos hábitos culturais, particularmente diante de atividades que "movem um grupo ou comunidade numa determinada região". Referidos hábitos, em um primeiro momento, foram incorporados em nossa Carta Magna de 1988 a partir da proteção das diferentes manifestações das culturas participantes do processo civilizatório, a saber, as culturas populares.

Devido o reconhecimento da atividade licita dos eventos de rodeio, o fator econômico passou a ser cada vez mais importante, já que muito dinheiro vem sendo investido. Com isso, a prática dessas modalidades se transformou em grandes eventos festivos e os animais passaram a ser também mais exigidos, o que aumentou o nível de violência, crueldade e maus tratos cometidos contra eles. Assim sendo, a questão cultural é constantemente colocada por seus praticantes como razão principal para a existência destas modalidades esportivas (Serra et al., 2003; Simon et al., 2018).

Dessa maneira, o artigo está dividido em três tópicos. O primeiro tópico irá abordar sobre a historicidade e origem dos rodeios, bem como a explanação legal dos instrumentos utilizados durante a realização desses eventos. Serão apresentados todos os equipamentos, artimanhas e apetrechos que os peões utilizam para que o animal pareça bravio. Logo, o segundo tópico irá dispor sobre as constituições brasileiras de proteção aos animais. Por certo, o constituinte objetivou, com a proteção da fauna e com a vedação, dentre outras, de práticas que "submetam os animais a crueldade", assegurar a efetividade do direito fundamental à preservação da integridade do meio ambiente natural. Vale salientar, portanto, que todos os animais devem gozar de direitos comuns, mesmo que nenhuma sociedade humana assim o reconheça. Esse é um direito que deve ser amplamente divulgado e reconhecido, contrapondo relativismos culturais e concepções religiosas. Enfim, o terceiro tópico busca apresentar normas gerais de fiscalização dos eventos em que ocorrem os rodeios, bem como demonstrar leis federais e projeto de lei que estabelece pena mais rígida para condutas cruéis praticadas contra os animais em espetáculos. A conclusão mostrará os parâmetros legais que visam garantir a integridade dos profissionais e dos animais, demonstrando com apoio de doutrinas e jurisprudências que infelizmente os animais sofrem abusos em manifestações culturais. 


\section{A proteção dos direitos dos animais no contexto do exercício dos rodeios no Brasil}

$\mathrm{Na}$ primeira parte desse artigo, são apresentadas informações relevantes acerca de conceitos, caracterização e instrumentos utilizados nos eventos de rodeios. A pesquisa se dará, inicialmente, através de um panorama histórico, trazendo informações da relação homem-animal desde os tempos antigos até a atualidade.

\section{Historicidade dos rodeios de gado}

O rodeio é competição esportiva que versa em um homem permanecer por até oito segundos sobre um animal (Dourado, 2003). Vigne (2011) relata que a cerca de doze mil anos atrás os animais e os homem já conviviam no mesmo espaço e foi nessa era que a raça humana iniciou a domesticação de animais selvagens para o sustento das necessidades alimentares. O homem, a partir da domesticação animal, pôde estabelecer-se e isso possibilitou o surgimento da sociedade. Desde então, os animais têm contribuído para o desenvolvimento humano (Ritvo, 2007). Dessa forma, resta claro que homem e animal desde os primórdios da humanidade conviveram. Contudo, esta convivência teve como base a utilidade dos animais na vida do homem.

\section{Origem e caracterização do rodeio}

A origem do rodeio é controversa e possui procedências distintas conforme os diferentes autores. Leira et al. (2016) afirmam que a prática do rodeio se originou na Espanha e foi adotada pelos mexicanos no final da guerra contra os norte-americanos no século XIX e logo se adaptou à América colonial inglesa. Por sua vez, Serra (2000) aduz que a origem da prática é originalmente mexicana, sendo que o próprio nome indica e pelo qual até hoje é conhecida: 'rodeio' vem do termo espanhol 'rodeo', de 'rodear', caracterizando a atividade de cercar o gado e apartá-lo nos currais.

\footnotetext{
"O rodeio teve início nas fazendas do oeste norte americano, no século XVII, após o sucesso dos Estados Unidos na guerra contra o México quando os trabalhadores, exibindo-se após a lida, apostavam quem possuía mais agilidade. Assim que o México foi conquistado pelos Estados Unidos, os peões levavam o gado para o Sul, fazendo paradas para folga durante o percurso. No tempo livre do trabalho, os trabalhadores brincavam de montaria e laço. Dessa forma, a brincadeira se tornou uma disputa amadora e, mais tarde, profissional (Serra, 2000)".
}

A entidade de defesa animal (ONCA, 2017) apresenta que foi na cidade de Colorado Springs, nos Estados Unidos, onde ocorreu a primeira prova de montaria, no ano de 1869, mas somente no início do século XX o rodeio passou a fazer parte de eventos públicos. O esporte é comum no Brasil, nos Estados Unidos, no México, no Canadá, na Austrália e em mais alguns países da América Latina. Os eventos, que aconteciam com periodicidade anual, atraíam públicos regionais e concorrentes ao longo do Oeste, e em 1920 ocorreu o campeonato em Boston e na Cidade de Nova Iorque, o que avocou a atenção de milhares de pessoas, proporcionando uma projeção nacional para o novo esporte(Serra, 2000). Em seu trabalho, Costa (2003) afirma que foi entre os anos de 1950 e 1970 que houve um crescimento do profissionalismo para a prática do rodeio.

"As entidades de rodeio norte americanas foram evoluindo cada vez mais e em 1975 foi criada a Profissional Rodeo Cowboy Association (PRCA), em Colorado Spring, e é até hoje considerada a maior associação de rodeio do mundo e já em sua criação nasceu tendo abrangência em 43 (quarenta e três) estados dos Estados Unidos, além de rodeios no Canadá, Austrália e na Nova Zelândia (Leira et al., 2016)".

A formação da National Intercollegiate Rodeo Association (NIRA) foi à base para expansão do rodeio às novas gerações de cowboys, e assim, o campeonato tornou-se mais profissional, já que os cowboys de cada modalidade precisavam participar de inúmeros circuitos regionais para conquistarem pontuação suficiente e concorrerem à premiação final.

No Brasil, estima-se que o rodeio tenha começado na década de 1950, naturalmente. A prática consolidou-se como esporte na cidade de Barretos, cuja principal atividade econômica era a pecuária extensiva, e onde também estavam localizados os maiores frigoríficos, responsáveis pelo abate dos animais e comercialização de toda a carne beneficiada (Leira et al., 2016). Foi nas regiões sudeste e centro-oeste, onde o rodeio sofreu maior influência norte-americana. As regras foram unificadas, caracterizando assim o esporte e trazendo novas modalidades valorizadas a nível mundial. $\underline{\text { Serra (2000) }}$ 
afirma que nos rodeios, o risco de vida e de acidentes com contusões e fraturas é maior do que com cavalos por lidar com animais pesados e fortes.

Sabe-se que os touros chegam a pesar mais de uma tonelada e alguns possuem chifres. Nesse tipo de montaria, não se utiliza sela e sim uma corda americana para segurar e mesmo assim apenas com uma das mãos a outra fica solta mantendo o equilíbrio, sem que o animal possa ser tocado (Vasconcelos et al., 2000).

Atualmente, com o crescimento profissional, reconhecimento e possibilidade de ascensão social a partir dos altos prêmios no rodeio, os cowboys precisaram se profissionalizar e hoje são viajados e bemeducados, articulados e empreendedores, preocupando-se também com a condição física, o que os possibilita manter a competitividade durante a longa temporada no ano.

\section{Instrumentos utilizados no rodeio}

Esse tópico utilizará como fonte principal o parecer de Martins (2014) elaborado como embasamento contrário ao Projeto de Lei de autoria do Senhor Vereador Alemão do Cruzado, que dispõe sobre a promoção e realização de rodeio no Município de Santo André/SP. Nos rodeios são utilizados equipamentos, artimanhas e apetrechos para que o animal pareça bravio e então seja domado pelos peões.

Vasconcelos et al. (2000) traz a informação que o sedém é aplicado na virilha, por ser uma região de pele fina bastante sensível, mas principalmente porque é a área onde se localizam os órgãos genitais. Em algumas provas, é realizado o corte do chifre do animal sem anestésico, causando sangramento e consequentemente dores. Acrescenta-se a tudo isso o transporte em condições precárias e o estresse do confinamento, no brete, antes das provas. Independentemente de ocasionarem, ou não, lesões aparentes, os instrumentos utilizados nas provas abrangidas por todas as modalidades do chamado "rodeio completo" impingem sofrimento aos animais. De acordo com Vasconcelos et al. (2000) e Ferreira (2011) no que tange aos instrumentos utilizados, destaca-se, em primeiro plano, o sedém que, como a própria definição revela, é um "cilício de cerdas ásperas e mortificadoras".

A promotoria de Justiça de São José dos Campos, demonstrando os maus-tratos e o sofrimento aplicados aos animais nas provas, traz se as conclusões da Dra. Prada, professora da Universidade de São Paulo, Titular da disciplina Anatomia da Faculdade de Medicina Veterinária e Zootecnia:

\footnotetext{
"De maneira particular, em relação aos rodeios, considerando-se as características de violência e agressividade das provas e treinamentos (...), a utilização de recursos inaceitáveis como o sédem e as esporas (...), a armação orgânica dos equinos e bovinos, passível de lesões corporais na ocorrência de quaisquer procedimentos violentos, bruscos e/ou agressivos (...), pode-se concluir que os sinais fisiológicos e comportamentais mostrados pelos animais, nos treinamentos e provas de rodeio, são coerentes com a vivência de dor/sofrimento (Rodrigues, 2014)".
}

Os animais são feridos com esporas nas provas de montaria e por esse motivo pulam e giram descontroladamente. Santos et al. (2011) aduzem que as esporas podem ser objetos pontiagudos ou não, e estão acoplados às botas dos peões, servindo para golpear o animal em alguma parte do corpo, que em conjunto com o sedém e outros equipamentos, força o animal a saltar de forma intensa. Além disso, quanto maior o número de golpes com as esporas, mais pontos são contados na montaria. Mas não só esporas são danosas, como também a utilização de peiteiras, sinos e também choques elétricos que forma clara, ocasiona sofrimento aos animais. Em resposta ao quesito específico, o perito e Professor Dr. Dirceu de Bortoli, citado no trabalho de Panicacci (2012) relatando a atuação por mais de vinte e cinco anos como médico veterinário afirma:

\footnotetext{
"Os equipamentos são causadores de lesões de vários tipos e amplitudes, desde lesões inflamatórias, cortantes ou escarificantes; estas últimas prontamente diagnosticáveis (...) além dos danos físicos, alguns são torturadores mentais, como por exemplo, os altos níveis de ruído, manejo impróprio, choques e cutucões etc."
}

Diante destes instrumentos citados, podemos especificar também a peiteira, que consiste em outra corda ou faixa de couro amarrada e puxada ao redor do corpo do animal, atrás da axila. A forte pressão que este instrumento exerce no animal acaba causando-lhe ferimentos e dor. Aliado à peiteira é adicionado outro instrumento chamado polaco, conjunto de sinos que são colocados para produzir barulho para ser irritante ao animal (Brandão, 2014). A professora Júlia Matera, presidente da comissão 
de ética da Faculdade de Medicina Veterinária e Zootecnia da Universidade de São Paulo, no Parecer Técnico sobre a potencialidade lesiva de sedém, peiteiras, choques elétricos e mecânicos e esporas em cavalos e bois diz que:

“A utilização de peiteiras, sedém, choques elétricos ou mecânicos e esporas gera estímulos que acarretam dor física nos animais, em amplitude que corresponde à intensidade dos estímulos. Além da dor física, tais estímulos acarretam também sofrimento mental aos animais, já que eles possuem capacidade neuropsíquica de avaliar que esses estímulos lhes são agressivos".

Existem ainda métodos utilizados nos bastidores do rodeio que não são presenciados pelo público, como objetos pontiagudos, e choques elétricos. Já é sabido cientificamente que o choque elétrico provoca rigidez muscular paralisando, portanto, a musculatura do animal, dificultando sua movimentação impedindo seu impulso para o salto (Brandão, 2014). Por sua vez, Kukul (2017) dispõe que devido aos massacres, práticas cruéis e abusos que os animais sofreram no decorrer da história, surgiu uma necessidade internacional de proteger os animais, com os países cooperando entre si para a defesa da fauna e flora que ainda restam no mundo, e desta maneira, a visão antropocêntrica ainda dominante, foi sendo superada e leis de proteção animal foram surgindo, ainda hoje as leis não são suficientes para livrar os animais totalmente da crueldade e abusos. Afinal, no ordenamento jurídico brasileiro, a garantia de proteção aos animais está prevista constitucionalmente, isso se torna um avanço em termos constitucionais, como será visto no segundo tópico, visto que, a luta por esta garantia no Brasil começou há quase cem anos, então temos o dever de proteger os animais e não submetê-los aos maus tratos e crueldades ou qualquer tipo de abuso, e fazer valer as leis que os protegem, pois a Constituição incumbiu também à coletividade e não somente o Ministério Público deste dever.

\title{
Evolução jurídica e argumentos favoráveis ao exercício da atividade dos rodeios
}

Nesse segundo tópico será apresentado o arcabouço legal que justifica o exercício da atividade dos rodeios, demonstrando imensas novidades em relação à defesa dos direitos e garantias do meio ambiente, valorizando as manifestações culturais. Veremos que o dever legal de defender e preservar o meio ambiente como bem de uso comum do povo e essencial à sadia qualidade de vida não incube somente ao Poder Público, mas também toda à coletividade.

\section{Os animais como sujeitos de direitos}

Antes de adentrarmos nos conceitos, e evoluções históricas das leis que defendem e preservem o meio ambiente. Inicialmente, deve-se observar se os animais podem ser titulares de direitos. Do ponto de vista filosófico, a questão dos direitos dos animais encontra nas raízes na teoria utilitarista de Bentham, que postulava no sentido de que, embora possam divergir do interesse do ser humano, os interesses dos animais devem ser igualmente respeitados (Brych, 2005). Montaigne, ao discordar da relação de parentesco entre os animais e os homens, salienta, entretanto, ao tratar de crueldade:

\footnotetext{
"Mais ainda que tudo isso seja discutível, cumpre-nos ter certo respeito, não somente pelos animais, mais também por tudo o que encerra vida e sentimento, inclusive árvores e plantas. Aos homens devemos justiça; as demais criaturas, capazes de lhes sentir os efeitos, solicitude e benevolência. Entre elas e nós existem relações que nos obrigam reciprocamente (Montaigne, 2002)".
}

Portanto, violências de todo gênero, por ação ou omissão, suscitam reações de indignação e comiseração da sociedade e desafiam a ordem jurídica. Inicialmente deve-se observar que a falta de personalidade, em si não prejudica os seres vivos em geral.

\begin{abstract}
"O animal como sujeito de direitos já é concebido por grande parte de doutrinadores jurídicos de todo o mundo. Assim como as pessoas jurídicas ou morais possuem direitos de personalidade reconhecidos desde o momento em que registram seus atos constitutivos em órgão competente, e podem comparecer em Juízo para pleitear esses direitos, também os animais tornam-se sujeitos de direitos subjetivos por força das leis que os protegem. Embora não tenham capacidade de comparecer em Juízo para pleiteá-los, o Poder Público e a coletividade receberam a incumbência constitucional de sua proteção. O Ministério Público recebeu a competência legal expressa para representá-los em Juízo, quando as leis que os protegem forem violadas (Kukul, 2017)”.
\end{abstract}

No que se refere à personalidade e à incapacidade, a ciência jurídica construiu modelo em que é feita a diferenciação entre a capacidade de gozo (potencial) e capacidade de exercício (efetiva), tal como ocorre no âmbito de incapacidades. Nada impede que os entes naturais tenham capacidade de direito, não obstante a exerçam por meio de representação de curadores ou tutores dos valores a eles associados 
(Farias, 2004). Conforme ensina dogmática analisada José Lutzemberger e citada na obra de Paulo Bessa Antunes faz a seguinte afirmação:

"Todas as espécies dominantes ou humildes, espetaculares ou apenas visíveis, que nos sejam simpáticas ou as consideremos desprezíveis, que nos afigurem como úteis ou mesmo nocivas, todas são peças de uma grande unidade funcional (Lutzemberger, 1976)".

Entretanto, os direitos ao meio ambiente saudável, por serem difusos, sem personificação determinada, não sendo de ninguém, podem e devem ser protegidos para o bem de todos (Art.225 da Constituição Federal). Onde o termo "todos" poderia englobar não só os homens, mas também com uma mudança de postura filosófica e jurídica, os seres vivos em geral (Farias, 2004).

\section{Evoluções históricas da proteção ao meio ambiente}

A função primordial do Direito Ambiental é organizar a forma pela qual a sociedade se utiliza dos recursos ambientais, estabelecendo métodos, critérios, proibições e permissões, definindo o que pode e o que não pode ser apropriado economicamente. Dessa forma, o surgimento do Direito Ambiental segundo o doutrinador Antunes "denota que as relações entre o Homem e o mundo que o envolve vêm se modificando de forma muito acelerada e profunda" (Fiorillo, 2009; Machado, 2014).

Analisando o contexto histórico brasileiro, percebe-se que no Brasil Imperial em 1824 inexistia qualquer referência acerca da proteção aos animais e dos recursos naturais, portanto, a proteção à fauna e a prática de maus tratos aos animais vem sendo mencionada somente a pós a década de 1930, com o advento da proclamação do Decreto Federal no 24.645/34. Diante de ampla evolução, o ano de 1941 também foi marcado pela proclamação do Decreto-Lei 3.688, conhecido como Lei das Contravenções Penais, onde prevê que a lei comina apenas prisão simples ou multa, ou ambas simultaneamente (Fiorillo, 2009). O primeiro dispositivo legal que visava à proteção dos animais foi proferido em São Paulo, em 1886. Trata-se do artigo 220 do Código de Postura do Município, que dispunha sobre a proibição a todo ferrador, cocheiro ou condutor de carroça de maltratar animais com castigos bárbaros e imoderados.

Assim, também no estado de São Paulo no ano de 2005 foi criado o Código e Proteção aos Animais (Lei ${ }^{\circ} 11.197$, de 2006) que vedou a realização ou a promoção de lutas entre animais da mesma espécie ou de diferentes em locais públicos e privados, vedando a apresentação ou utilização de animais em espetáculos que envolvam uso de instrumentos que induz o animal à um comportamento que não se produziria naturalmente. Dessa forma, em contraposição ao Estado e aos cidadãos, ao público e ao privado, iniciou-se no Brasil, com a Constituição Federal de 1988 uma nova categoria de bens: os bens de uso comum do povo e essenciais à sadia qualidade de vida (Fiorillo, 2009).

A fruição do meio ambiente saudável e ecologicamente equilibrado foi erigida em direito fundamental. A adequada compreensão dos capítulos e dos dispositivos constitucionais voltados para o meio ambiente é essencial e exige uma atenção toda especial para disciplinas não jurídicas. Dessa forma, segundo o doutrinador Antunes "A norma constitucional ambiental é parte integrante de um complexo mais amplo e podemos dizer, sem risco de errar, que ela faz a interseção entre as normas de natureza econômica e aquelas destinadas à proteção dos direitos individuais" (Machado, 2014).

\section{Instrumentos legais em defesa ao meio ambiente}

Nesse sub-tópico serão apresentados os instrumentos legais em defesa ao meio ambiente no que se refere o uso de animais como seres detentores de direitos.

- Aspectos gerais da constituição de 1988

O capítulo do meio ambiente da Constituição Federal é o centro nevrálgico do sistema constitucional de proteção ao meio ambiente como um elemento de interseção entre a ordem econômica e os direitos individuais. Em razão da alta relevância do bem jurídico tutelado, a lei fundamental estabeleceu a obrigação do Poder Público e da comunidade de preservá-lo para as presentes e futuras gerações.

Ferreira (2011) acredita que o artigo 225 da Constituição, foi um marco ambientalista, destacando a maturidade e inovação do legislador, que estabeleceu novos parâmetros na relação entre os homens e os animais, inserindo o artigo acima supracitado no Título que dispõe sobre a Ordem Social, cabendo ao 
Estado e a coletividade a proteção e o respeito aos animais. Em vista disso, compreende-se que o art. 225 da Constituição Federal de 1988, ampara normas com direito e deveres destinados à sociedade como fins e objetivos ao Estado para que atue em prol do interesse público. O preenchimento desse conceito possibilitou em parte a recepção da Lei n 5.197/67 (Lei de Proteção à Fauna), que determina, em seu art. $1^{\circ}$, que:

\begin{abstract}
"Art. $1^{\circ}$. Os animais de quaisquer espécies, em qualquer fase do seu desenvolvimento e que vivem naturalmente fora do cativeiro, constituindo a fauna silvestre, bem como seus ninhos, abrigos e criadouros naturais são propriedades do Estado, sendo proibida a sua utilização, perseguição, destruição, caça ou apanha (BRASIL, 1967)".
\end{abstract}

O Legislador constituinte não pretendeu limitar a fauna, mais sim, planejar que a lei busque preservála, resguardando das práticas que coloquem risco a função ecológica e à extinção das espécies e que submetem os animais a crueldade (Fiorillo, 2009).

Todavia, não se olvidou nossa Carta Magna de igualmente observar à tutela jurídica evidenciada pelos novos hábitos criados por força da fortíssima influência dos meios de comunicação social, principalmente em face da programação de emissoras de rádio e de televisão. Por via de consequência, os diferentes temas vinculados à cultura brasileira e, portanto, as manifestações culturais necessariamente passaram a se submeter também aos novos hábitos culturais.

O parágrafo I, inciso I do art.225 da Lei Fundamental estabelece não somente obrigações para o Poder Público, mas também um direito subjetivo Público contrário ao Estado, estabelecendo maneiras que o cidadão possa exigir que o Estado trabalhe ativamente na área da proteção ao meio ambiente (Andrade, 2003).

"Parágrafo $1^{\circ}$ Para assegurar a efetividade deste direito, incumbe ao poder público:

I - Preservar e restaurar os processos ecológicos essenciais e prover o manejo ecológico das espécies e ecossistemas (BRASIL, 1988)".

Devido o complexo amplo de teor de direitos, o artigo 225 exerce o papel principal norteador do meio ambiente. Possuindo uma série de normas esparsas no texto constitucional que devem ser respeitadas para que haja uma cidadania ao meio ambiente saudável. A constituição não somente visa proteger as normas de natureza econômica, mais também à proteção dos direitos individuais (ㅁantos, 2012).

\title{
- Aspectos gerais da Declaração Universal dos Direitos dos Animais
}

Em assembleia realizada em 1978, a Organização das Nações Unidas para a Educação, Ciência e Cultura (UNESCO, 1978) programou a Declaração Universal dos Direitos dos Animais, estabelecendo princípios e diretriz destinada a toda humanidade. A Declaração Universal dos Direitos dos Animais, semelhantemente a Constituição Federal de 1988 aduz que todos os animais têm o direito de viver e crescer sobre a atenção, proteção e aos cuidados do homem para as suas condições de vida e de liberdade. Neste contexto, a lei estabelece, portanto que nenhum animal deve ser explorado para divertimento do homem, e nem exibido em espetáculos que são incompatíveis com a sua dignidade.

Assim sendo, a declaração busca proteger a sobrevivência de todas as espécies, mais, sobretudo, defender uma existência íntegra e digna aos animais. $\mathrm{O}$ art. $14^{\circ}$ da Declaração aduz que "Os organismos de proteção e de salvaguarda dos animais devem estar presentados a nível governamental, e os direitos do animal devem ser defendidos pela lei como os direitos do homem” (UNESCO, 1978).

A prática a solidariedade, fraternidade, consciência, responsabilidade, e do comprometimento são premissas indispensáveis a serem adotadas pelo leitor para o entendimento e o sucesso desta abordagem, que visa não só proteger a sobrevivência de todas as espécies, mas, sobretudo, defender uma vida plena aos animais e aos humanos.

\section{A importância da fiscalização ambiental para proteção e conservação ao meio ambiente ecologicamente equilibrado}

Esse tópico tem como objetivo apresentar as normas gerais de fiscalização que dispõe a realização dos eventos em que ocorrem os rodeios, bem como demonstrar a importância do novo Projeto Lei $\mathrm{n}^{\circ}$ 4564/2016 que estabelece pena mais severa para condutas cruéis praticadas contra os animais. Em vista, 
o presente artigo irá delimitar regras aos apetrechos técnicos utilizados nas montarias para garantir a proteção da integridade dos profissionais e dos animais, demonstrando com o apoio de jurisprudências pátrias que os animais sofrem abusos em manifestações culturais.

\section{Legalidade da atividade esportiva regulamentada pela Lei $n^{\circ}$ 10.220/2001}

A lei no 10.220, aprovada dia 11 de abril de 2001 instituiu normas gerais relativas às atividades de peões de rodeios como atleta profissional, regulamentando assim à profissão.

No ano de 2001, após a normatização da profissão de peão, foi formada a Confederação Nacional de Rodeio, com objetivo de organizar, dirigir e incentivar, em todo território nacional, a prática do rodeio, fiscalizando e promovendo os eventos e campeonatos estaduais e nacionais em todas as modalidades, exercendo um trabalho em conjunto com as Federações Estaduais de Rodeio (CNAR, 2014).

Para compreender melhor o que diz a Lei $\mathrm{n}^{\circ} 10.220$ acerca do assunto é necessário estabelecer a definição do que sejam peões de rodeios. Essa definição está elencada no artigo $1^{\circ}$ da lei acima supracitada, vejamos:

\footnotetext{
"Art. 1 Considera-se atleta profissional o peão de rodeio cuja atividade consiste na participação, mediante remuneração pactuada em contrato próprio, em provas de destreza no dorso de animais equinos ou bovinos, em torneios patrocinados por entidades públicas ou privados.

Parágrafo único. Entendem-se como provas de rodeios as montarias em bovinos e equinos, as vaquejadas e provas de laço, promovido por entidades públicas ou privado, além de outras atividades profissionais da modalidade organizadas pelos atletas e entidades dessa prática esportiva (BRASIL, 2001)".
}

A princípio a legislação dá direito ao contrato, à remuneração, a seguro de vida e de acidentes, ressarcimento de despesas médicos hospitalares em caso de acidentes, bem como às terapias que se fizerem necessárias para a recuperação do acidentado. Portanto a lei não estabelece limites para o horário de trabalho dos animais, mais determina jornada máxima de 8 horas de trabalho para os peões (BRASIL, 2001). Todavia, a atividade esportiva se apresenta à atividade contemporânea como um fenômeno de grande abrangência social, tanto do ponto de vista do espetáculo, como da atividade profissional. Em virtude disso, o comportamento respeitoso fundamenta esse esporte e deve por certo nortear a legislação desportiva, protegendo o instrumento promocional do desenvolvimento e da paz, afastando a crueldade e maus tratos com os animais.

\section{Proteção da integridade física dos animais e dos atletas profissionais dos rodeios conforme a Lei $n^{\circ}$ 10.519/2002}

No Brasil, o rodeio está regulamentado pelas Leis Federais $n^{\circ} 10.220 / 2001$, que foi mencionado no tópico anterior, e pela lei $\mathrm{n}^{\circ} 10.519 / 2002$. A lei federal $\mathrm{n}^{\circ} 10.519$ vigente a mais de 10 anos, promulgada em Julho de 2002, tem como objetivo geral dispor sobre a fiscalização da defesa sanitária animal, quando da realização de rodeio e de outras providências. A lei ao dispor sobre esse objetivo geral acabou por compatibilizar a proteção jurídica do meio ambiente natural em face do meio ambiente cultural e do trabalho, harmonizando no plano infraconstitucional a defesa da fauna em face dos modos de viver de alguns brasileiros em determinadas regiões do País.

Para o doutrinador Fiorillo (2009), as entidades promotoras do rodeio passam a ter, por força de lei, algumas obrigações, destinadas não só a resguardar a integridade física dos profissionais que atuam nas atividades como a própria integridade física dos animais participantes do evento. No que se refere aos profissionais à lei no seu Artigo $3^{\circ}$ determina caber às entidades promotoras do rodeio, a suas expensas, prover:

I - Infraestrutura completa para atendimento médico, com ambulância de plantão e equipe de primeiros socorros, com presença obrigatória de clínico-geral;

III - transporte dos animais em veículos apropriados e instalação de infraestrutura que garanta a integridade física deles durante sua chegada, acomodação e alimentação;

IV - Arena das competições e bretes cercados com material resistente e com piso de areia ou outro material acolchoador, próprio para o amortecimento do impacto de eventual queda do peão de boiadeiro ou do animal montado (BRASIL, 2002).

A lei também estabeleceu regras vinculadas aos apetrechos técnicos utilizados nas montarias no âmbito da realização de rodeios no sentido de delimitar, no plano infraconstitucional, a determinação estabelecida na Constituição Federal. Os acessórios mencionados no primeiro tópico não poderão 
conforme determina o art. $4^{\circ}$ dessa lei, causar injúrias ou ferimentos aos animais, devendo então obedecer às normas estabelecidas pela entidade representativa do rodeio, que deverá por sua vez apoiarse naquilo que a lei chama de "regras internacionais aceitas". A lei estabelece ainda que alguns apetrechos utilizados nas montarias de rodeios, como as cintas, cilhas e barrigueiras, deverão obrigatoriamente ser confeccionadas em lã natural, com dimensões adequadas, para garantir o que o legislador chama de "conforto dos animais". O uso de esporas com rosetas pontiagudas ou qualquer outro instrumento destinado a ocasionar ferimento nos animais, tais como chicotes, passa a ser expressamente proibido por lei inclusive aparelhos que provoquem choques elétricos. A partir das normas gerais contidas nesta lei, os organizadores ficam autorizados a promover a realização dos rodeios. Desde que comuniquem ao órgão estadual competente a realização das provas com antecedência mínima de trinta dias, demonstrando aptidão legal para cumprir com suas obrigações em todos os planos. E para efeitos do que estabelece o art. $3^{\circ}$, II os organizadores devem apresentar desde o principio, o médico veterinário responsável, comprovando assim estar apta a realização do evento seguindo as normas legais.

As condutas e atividades consideradas pela lei sujeitarão os infratores (pessoas físicas ou jurídicas vinculadas à atividade) não só às sanções administrativas indicadas no art. $7^{\circ}$, I a III (advertência por escrito, suspensão temporária e suspensão definitiva do rodeio, que se aplicam evidentemente apenas em face da atividade econômica organizada, como as outras penalidades previstas em legislação específica" , o que nos leva a observar necessariamente a aplicação também da Lei n.9.605/98 em matéria criminal e da Lei $\mathrm{n}^{\circ}$ 6.938/81 demais normas cabíveis no plano da obrigação de reparar dano causado.

\section{Da novidade trazida pelo novo Projeto de Lei $n^{\circ} 4564 / 2016$}

O projeto de lei $\mathrm{n}^{\circ} 4564 / 2016$ define a conduta de maus tratos praticada contra os animais e estabelece punição mais severa. Semelhantemente as leis anteriormente citadas, o projeto de lei reconhece que qualquer prática desnecessária onde submetem os animais à crueldade deve ser proibida pelo nosso ordenamento jurídico.

Diante disso, o autor da proposta deputado Francisco Floriano, do Rio de Janeiro, especifica no novo projeto de lei, condutas de maus tratos que são consideradas abusivas e intoleráveis contra os animais:

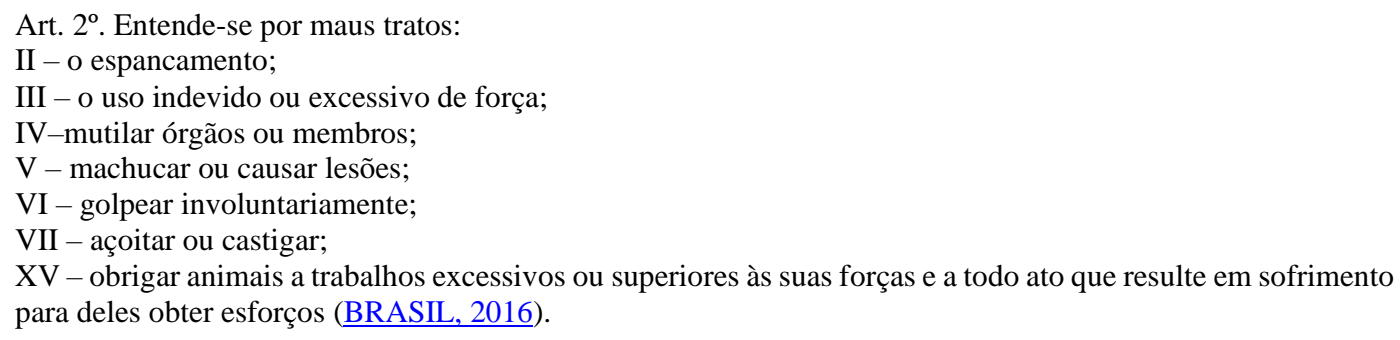

As condutas que estão tipificadas no artigo anterior, não excluem outras decorrentes da ação ou omissão, dolosa ou culposa, cruel, grave e prejudicial, que exponha a perigo ou cause dano à saúde ou ao bem estar físico e psíquico do animal ou que de qualquer modo, na sua morte.

O que se nota de vantagem no projeto lei é que diferentemente da Lei de crimes ambientais (Lei $\mathrm{n}^{\circ}$ $9.605 / 98$ ), o projeto $\mathrm{n}^{\circ} 4564 / 2016$ visa no $\S 1^{\circ}$ do art. $2^{\circ}$, aumentar a penalidade para coibir essas praticas.

Art. $2^{\circ}$. Constitui crime praticar atos de maus-tratos contra os animais.

Pena - reclusão, de 2 (dois) a 8 (oito) anos.

$\S 1^{\circ}$ A pena é aumentada em dobro se o crime foi praticado pelo dono (BRASIL, 2016).

Dessa forma a lei $n^{\circ} 9.605 / 98$ (lei de crimes ambientais) estabelece em seu art. $29^{\circ}$ detenção de seis meses a um ano, e multa. Já o projeto de lei ${ }^{\circ} 4564 / 2016$, dispõe em seu art. $2^{\circ}$ a majoração da pena, sendo, portanto, à reclusão, de 2 (dois) a 8 (oito) anos.

Sem adentrar aos debates doutrinários, o que ninguém discorda é que a pena imposta a uma determinada conduta deve ser compatível com o resultado danoso para a sociedade. Ou seja, a punição deve ser proporcional ao bem jurídico violado que, no caso em questão, é a integridade física dos animais. 
Sanções penais e administrativas aplicáveis ao descumprimento às ordens impostas pela Lei dos Crimes Ambientais

A proteção da biodiversidade nacional, por influência de diversos tratados internacionais, teve na Lei $\mathrm{n}^{\circ}$ 9.605/98 um instrumento mais adequado, tendo a crueldade contra os animais elevando-se à categoria de crime, quando até o advento de tal lei, consistia o ato em mera contravenção penal (Vieira, 2016).

A Lei Federal no 9.605/98, conhecida como Lei dos Crimes Ambientais (LCA), dispõe sobre as sanções penais e administrativas derivadas de condutas e atividades lesivas ao meio ambiente, estipulando penas para quem as descumpre. Aduz o Diz o artigo 32 da Lei $n^{\circ}$ 9.605/98:

Art. 32. Praticar ato de abuso, maus-tratos, ferir ou mutilar animais silvestres, domésticos ou domesticados, nativos ou exóticos. Pena - detenção, de três meses a um ano, e multa.

$\S 1^{\circ}$ Incorre nas mesmas penas quem realiza experiência dolorosa ou cruel em animal vivo, ainda que para fins didáticos ou científicos, quando existirem recursos alternativos.

$\S 2^{\circ}$ A pena é aumentada de um sexto a um terço, se ocorre morte do animal (BRASIL, 1998).

De qualquer maneira, a lei devidamente aplicada, configura-se atualmente importante instrumento destinado a defender assim como os bens ambientais.

A administração ambiental tem como finalidade obrigar os órgãos da União, Estados, Municípios e Distrito Federal a defender e preservar os bens ambientais para as presentes e futuras gerações antes a proteção indicada pela Constituição Federal aos interesses difusos e coletivos em proveito da dignidade da pessoa humana (Brandão, 2014; Kukul, 2017)).

\section{Jurisprudências}

- Peão de rodeio tem recurso provido em favor do descumprimento do exposto na Lei $\mathrm{n}^{\circ}$ $10.220 / 2001$

Processo TRT - RO - 0000711-27.2012.5.18.0141

Relatora: Dra . JuízaSilene Aparecida Coelho

Recorrente: Jean De oliveira Soares

Advogados: Gustavo Muniz Feitosa e Outros

Recorrido: Município de Campo Alegre de Goiás

Advogados: Edivaldo de Jesus Peixoto e Outros

Origem: Vt de Catalão

Dro: Juiz Édison Vaccari

Orgão Julgador: $1^{\mathrm{a}}$ TURMA

Julgamento: 6 de fevereiro de 2013

O entendimento jurisprudencial da primeira Turma do Egrégio Tribunal Regional do Trabalho da $18^{\mathrm{a}}$ Região, que por unanimidade, deu provimento ao recurso em que o reclamado Jean De Oliveira ajuizou em face do Município de Campo Alegre de Goiás. O reclamante ajuizou reclamatória com vistas a obter reparação por danos materiais e morais decorrentes de acidente por ele sofrido quando da atuação em prova de montaria realizada em rodeio promovido pelo município reclamado. Observando que mesmo não havendo contratação do reclamante com o reclamado, ou ajuste de pagamento de salário para a participação do rodeio, o fato não é capaz de desnaturar o contrato de trabalho, visto que efetivamente ocorreu a prestação de serviço, pois o reclamante realizou a montaria.

Desta forma, $o$ art. $1^{\circ}$ da Lei 10.220//2001 estabelece que a remuneração de atletas profissionais de rodeio deve ser pactuada em contrato próprio, sendo obrigatória a contratação de acidentes em favor dos peões de rodeios, compreendendo indenizações por morte ou invalidez, permanente no valor mínimo de cem mil reais. Ainda mais, a entidade que estiver com pagamento da remuneração em atraso, não poderá participar de qualquer competição, oficial ou amistosa. Diante disso, como já vimos a Lei 10.220/2001 reconheceu a participação em montarias nos rodeios como atividade profissional, estabelecendo uma série de direitos para a categoria dos peões que atuam nesse ramo, e, portanto resta evidente que o legislador buscou conferir as relações havidas entre os peões de rodeio e a entidade promotora do evento, não havendo como negar a existência de relação de trabalho nesses casos. 
- Proibição de qualquer instrumento que provoque maus tratos contra os animais: aplicabilidade da Lei $n^{\circ} 10.519 / 02$

Processo: APL 00023821020128260498 SP 0002382-10.2012.8.26.0498

Relatora: Dr ${ }^{\circ}$ Juiz Moreira Viegas e participação dos Exmos.

Desembargadores Zélia Maria Antunes Alves (Presidente) e Torres de Carvalho.

Recorrente: Prefeitura Municipal de Boa Esperança do Sul e Arena Show Locações e Eventos LtdaEpp.

Recorrido: Ministério Público de Boa Esperança do Sul.

Órgão Julgador: $1^{\mathrm{a}}$ Câmara Reservada ao Meio Ambiente.

Julgamento: 18 de Julho de 2013.

A ação ajuizada em que são apelantes a Prefeitura Municipal de Boa Esperança do Sul e a Arena Show Locações e Eventos Ltda. Epp é apelado Ministério Público do Estado de São Paulo. O Poder Judiciário do Estado de São Paulo acordaram em $1^{\text {a }}$ Câmara Reservada ao Meio Ambiente, julgando procedentes o pedido para proibir, em qualquer "Festa do Peão de Boa Esperança do Sul, especificamente nas montarias em bois, touros e cavalos (sejam animais de qualquer idade), a utilização de instrumentos provocadores de maus tratos contra animais protagonistas das montarias, como sedém (qualquer deles), esporas (qualquer delas), choques, peiteiras, laços e outros ante a inequívoca crueldade e maus tratos que aludida atividade causa aos animais, independentemente do disposto na Lei $\mathrm{n}^{\circ} 10.519 / 02$, que nesta decisão é declarada inconstitucional, sob pena de multa diária no valor de R \$ 10.000,00 (dez mil reais), por dia de descumprimento e, diante da sucumbência, condenou as requeridas a suportar as custas processuais.

A mercê de tais considerações, a Lei $n^{\circ}$ 10.519/02 reconhece a possibilidade de se realizar rodeios, dispondo expressamente no art.4 que: "Os apetrechos técnicos utilizados nas montarias, bem como as características do arreamento, não poderão causar injúrias ou ferimentos aos animais e devem obedecer às normas estabelecidas pela entidade representativa do rodeio, seguindo as regras internacionalmente aceitas" (BRASIL, 2002).

Aliando-se com os princípios constitucionais de proteção ao meio ambiente. Vale destacar, contudo, que isso não impede que essa questão seja enfrentada em âmbito inconstitucional, principalmente no que concerne à própria realização do rodeio.

Portanto, mesmo o Município não sendo o patrocinador da festa, deve zelar pela aplicação dos princípios constitucionais ambientais, o que decorre da observância do art. 23 da Constituição Federal de 1988. Assim sendo, é evidente que na concessão de alvará de autorização para a realização dos rodeios deve se ater a tais regramentos, ante a incidência do poder de polícia preventivo e repressivo.

\section{Considerações finais}

A partir da segunda metade do século XX, os bens de natureza difusa passaram a ser objeto de maior preocupação pelo aplicador do direito e mesmo pelos cientistas e legisladores como um todo. Qualquer esporte ou competição em que o adversário é um animal em desvantagem configura-se no mínimo como uma atividade covarde e por sua natureza cruel.

Dessa forma, as legislações federais estão crescendo cada dia mais em prol do padrão de vida dos humanos e dos animais. Vale destacar que essas competências foram ampliadas modernamente nas áreas que são classificadas como infraestrutura, isto é, atividades necessárias para o desenvolvimento econômico.

A Constituição Federal trouxe imensas novidades em relação as que antecederam notadamente na defesa dos direitos e garantias individuais e no reconhecimento de nova gama de direitos, dentre os quais se destaca o direito as praticas que coloquem em risco a função ecológica e provoquem a extinção de espécies ou submetam os animais à crueldade.

Podemos concluir que as novas normas jurídicas ambientais, como a Constituição Federal de 1988, a Lei $n^{\circ} 9.605 / 1998$, a Lei $n^{\circ} 10.220 / 2001$, a Lei $n^{\circ} 10.519 / 2002$, e até mesmo o Projeto de Lei $n^{\circ}$ 4564/2016 demonstram a urgência de que as práticas chamadas esportivas ou as culturais sejam adequadas à segurança e ao bem-estar do animal, que tem direito à vida e de não ser submetido à dor nem ao sofrimento. 
Portanto, não pensem que o Brasil é pobre em leis em combater os maus-tratos aos animais. Neste sentido, em verdade, nosso país é pródigo em leis, mais incipiente na sua aplicação. O combate aos maus tratos praticados contra animais é uma missão de toda sociedade e não só o Poder Público. O trabalho de educação em todos os níveis e, inclusive, com campanhas publicas de conscientização, se constitui um forte aliado das leis, pois todos são responsáveis por garantir o bem-estar dos animais.

Além disso, práticas como rodeios, entre outras, têm sido alvo de muitas críticas e para alguns se comparam ao holocausto. Exageros à parte é preciso estabelecer limites, e não a extinção sumária de todas essas atividades. Existe, claramente, um conflito cultural evidenciando que as práticas mais violentas, como os rodeios, durante as quais os animais são torturados de forma cruel, não podem persistir.

Nesse sentido, vale ressaltar que a finalidade do artigo não se posiciona na compreensão de que as manifestações culturais devem ser proibidas, mais somente evitar os abusos contra os animais que não podem defender-se das brutalidades praticadas pelo homem, porque sabemos que todas essas práticas são vedadas pela legislação brasileira.

\section{Referências bibliográficas}

Andrade, H. F. X. d. (2003). O princípio ecológico da proteção e utilização e o direito à propriedade rural no Brasil no atendimento a sua função social: uma abordagem histórico-jurídica-sistêmica.

Brandão, I. M. (2014). Crimes ambientais: uma visão sobre as práticas do rodeio e da vaquejada. Interfaces Científicas-Direito, 2(2):93-104.

BRASIL, Constituição da República Federativa do Brasil de (1988). Disponível em:< http://www.planalto.gov.br/ccivil_03/Constituicao/Constituicao.htm>. Acesso em: 10 de jul. de 2017.

BRASIL, Lei $\mathrm{n}^{\circ}$ 5.197, de 03 de janeiro de (1967). Dispõe sobre a proteção à fauna e dá outras providências. Disponívelem :http://www.planalto.gov.br/ccivil_03/leis/L5197.htm .

BRASIL, Lei ${ }^{\circ}$ 6.938, de 31 de agosto de 1981. Dispõe sobre a Política Nacional do Meio Ambiente, seus fins e mecanismos de formulação e aplicação, e dá outras providências. Disponivelem :http://www.planalto.gov.br/ccivil_03/leis/L6938.htm

BRASIL, Lei $\mathrm{n}^{\circ}$ 9.605, de 12 de fevereiro de 1998.Dispõe sobre as sanções penais e administrativas derivadas de condutas e atividades lesivas ao meio ambiente, e dá outras providências. Disponível em: Acesso em: 10 Out. 2017.

BRASIL, Lei ${ }^{\circ} 10.220$, de 11 de abril de (2001). Institui normas gerais relativas à atividade de peão de rodeio, equiparando-o a atleta profissional. Disponível em: Acesso em: 10 Out. 2017.

BRASIL, Lei ${ }^{\circ}$. 10.519, de 17 de julho de (2002).Dispõe sobre a promoção e a fiscalização da defesa sanitária animal quando da realização de rodeio e dá outras providências. Disponível em: . Acesso em: 08 Out. 2017.

BRASIL, Lei n ${ }^{\circ}$ 11.197, de 03 de agosto de (2006). Institui o Código de Posturas no Município de Juiz de Fora e dá outras providências. Disponível em: http://www.camarajf.mg.gov.br/mostra_anexo.php?tipo=CODPOST. Acesso em: 20 Out. de 2017.

BRASIL. Decreto $n^{\circ}$ 24.645, de 10 de Julho de 1934. Estabelece medidas de proteção aos animais. Disponível em :http://funed.mg.gov.br/wp-content/uploads/2010/05/Decreto-lei-24645-34-maustratos-animais.pdf

BRASIL. Decreto ${ }^{\circ}$ 11.977, de 25 de Agosto de 2005. Institui o Código de Proteção aos Animais do Estado e dá outras providências. Disponível em :https://www.al.sp.gov.br/norma/?id=57021

Brych, F. (2005). Ética utilitarista de Jeremy Bentham. Âmbito Jurídico, Rio Grande, 23(30):11.

Costa, S. P. (2003). Esporte e paixão: o processo de regulamentação dos rodeios no Brasil. Movimento, 9(2):71-87.

BRASIL, (2016). Câmara dos Deputados do Brasil. Projeto Lei no 4.564 de 25 de fevereiro de 2016. Esta Lei define a conduta de maus tratos praticada contra os animais e estabelece punição. Disponível 
em: $<$ http://www.camara.gov.br/proposicoesWeb/prop_mostrarintegra?codteor=1436816\&filename $=\mathrm{PL}+4564 / 2016>$.Acesso em: 12 de jul. De 2017.

CNAR, 2014

Declaração Universal dos Direitos dos Animais. Unesco/ONU. Bruxelas - Bélgica, 27 de janeiro de 1978. Disponível em: <http://portal.cfmv.gov.br/portal/uploads/direitos.pdf>. Acesso em: 21 ago. 2017.

Dourado, S. P. C. (2003). Esporte e Paixão: o processo de regulamentação dos rodeios no Brasil. Movimento, 9(2):74-86.

Farias, P. J. L. (2004). Proteção dos Animais. Revista Jurídica Consulex, VII(174).

Ferreira, A. C. B. (2011). Animais não humanos como sujeitos de direito: considerações processuais. Revista Brasileira de Direito Animal, 6(9):307-353.

Fiorillo, C. A. P. (2009). Curso de direito ambiental brasileiro. São Paulo: Saraiva.

Kukul, I. M. (2017). Maus tratos aos animais: A análise da constitucionalidade das festas de rodeio. Contribuciones a las Ciencias Sociales, 11-10.

Leira, M. H., Reghim, L. S., Peregrino, L. C., Honda, C. N., Félix, J. I. C., Silva, F., . . Cunha, L. T. (2016). A origem do rodeio no Brasil sua prática como esporte radical e o bem-estar dos animais de montaria. PUBVET, 11207-312.

Lutzemberger, J. (1976). Mnifesto ecológico. Porto Alegre, Rio Grande do Sul, Brasil: Editora Lançamento.

Machado, P. A. L. (2014). Direito ambiental brasileiro. São Paulo: Ed. Revista dos Tribunais.

Martins, R. de F. (2014). Rodeios: cultura e esporte ou prática cruel e desprovida de identidade, 2014. Disponívelem: <http://www.ranchodosgnomos.org.br/rodeios_crueldade.php.>. Acesso em: 21 ago. 2017.

Minosso, L. A., Santos, M. D., Toma, H. S., Toma, C. D. M., Costa, D. S., Junior, D. A. F. \& Lopes, F. G. (2014). Manejo de rodeio diário como ferramenta para incrementar a taxa de prenhes de vacas Nelore. Revista Brasileira de Higiene e Sanidade Animal: RBHSA, 8(2):39-51.

Montaigne, M. (2002). Os ensaios: livro I. São Paulo, Brasil: Nova Cultura.

ONCA, Entidade de Defesa aos Animais. Depoimentos, 2017. Disponível em: <http://www.onca.net.br/quem-somos-2/quem-somos/>. Acesso em: 23 set. 2017.

Panicacci, F. L. (2012). Os rodeios e a jurisprudência paulista sobre as práticas que submetem animais a crueldade. Hortolandia News, 1-27.

Ritvo, H. (2007). On the animal turn. Daedalus, 136(4):118-122.

Rodrigues, I. S. (2014). A atividade do Rodeio no Brasil. Revista Jusbrasil. Disponível em: <https://sobre.jusbrasil.com.br//artigos/155145930/a-atividade-do-rodeio-no-brasil>.

Santos, A. L. Q., Rodrigues, T. C. S., D'Aparecida, N. S., Silva Júnior, O. T., Moraes, F. M., Moreira, M. R. \& Massuda, P. (2011). Efeito dos equipamentos utilizados em touros de rodeio. PUBVET, 5115.

Santos, E. (2012). O princípio da proibição do retrocesso socioambiental e o "novo" Código Florestal. Revista de Direito Econômico e Socioambiental, 3(2):505-529.

Serra, R. (2000). Rodeio--uma paixão! : Gryphus.

Serra, R. A. A., Tubino, M. J. G. \& Silva, N. J. (2003). O rodeio como uma manifestação esportiva de identidade cultural do interior de São Paulo. Fitness \& Performance Journal, 2(6):341-346.

Simon, V., Zago, L., Magalhães, D. R., Levrino, G. A. M., Sañudo, C. \& Kirinus, J. K. (2018). O rodeio como uma prática esportiva de identidade cultural na região Sul do Brasil. PUBVET, 12(11):1-6. doi: http://dx.doi.org/10.31533/pubvet.v12n11a201.1-6.

Vasconcelos, O. T., Alessi, A. C., Esper, C. R. \& Franceschin, P. H. (2000). Avaliação técnico-científica da utilização do sedém em bovinos de rodeio. Revista de Educação Continuada em Medicina Veterinária e Zootecnia, 3(2):72-77. 
Vieira, T. R. (2016). Biodireito, animal de estimação e equilíbrio familiar: apontamentos iniciais. Revista de Biodireito e Direito dos Animais, 2(1):179-195.

Vigne, J.-D. (2011). The origins of animal domestication and husbandry: a major change in the history of humanity and the biosphere. Comptes Rendus Biologies, 334(3):171-181.

Recebido: 13 de janeiro, 2020.

Aprovado: 31 de janeiro, 2020.

Publicado: 29 de fevereiro, 2020.

Licenciamento: Este artigo é publicado na modalidade Acesso Aberto sob a licença Creative Commons Atribuição 4.0 (CC-BY 4.0), a qual permite uso irrestrito, distribuição, reprodução em qualquer meio, desde que o autor e a fonte sejam devidamente creditados. 